\title{
Measuring quality of life in rheumatic conditions
}

\author{
Janine G. Walker • Geoffrey O. Littlejohn
}

Received: 14 September 2006 / Accepted: 14 September 2006 / Published online: 24 November 2006

(C) Clinical Rheumatology 2006

\begin{abstract}
Musculoskeletal disorders often have associated pain, functional impairment and work disability, and, not surprisingly, are the most common reasons for utilizing healthcare resources. Rheumatoid arthritis (RA) and fibromyalgia (FM) are causes of musculoskeletal pain and disability. Research indicates that there is a widespread impact of RA and FM on physical, psychological and social factors in affected individuals, and thus, outcome measures that encompass multiple aspects of quality of life are needed. Generic measures of quality of life identify associations between physical conditions and mental health and highlight the need to address psychological functioning to ultimately improve the individuals' quality of life.
\end{abstract}

Keywords Disability · Fibromyalgia ·

Quality of life · Rheumatoid arthritis

Musculoskeletal disorders often have associated pain, functional impairment and work disability, and, not surprisingly, are the most common reasons for utilizing healthcare resources $[1,2]$. Rheumatoid arthritis (RA) and fibromyalgia (FM) are among the most common causes of musculoskeletal pain and disability. They are estimated in community studies to affect $0.5-1$ and $2-6 \%$ of the population, respectively [3-5]. These two conditions differ in a number of ways: In particular, RA has a clear pathophysiology with a range of clinical measures being

\section{J. G. Walker $(\bowtie)$}

Centre for Mental Health Research,

Australian National University,

Canberra 0200, Australia

e-mail: janine.walker@anu.edu.au

G. O. Littlejohn

Department of Medicine, Monash University,

Melbourne, Australia able to indicate its presence, whereas the biological basis for FM is less defined with no "gold standard" test available. Despite this difference, these two rheumatic conditions share a range of associated outcomes. These include not only pain and fatigue but also difficulties with activities of daily living, ranging from basic and intermediate functions through to more complex tasks such as paid employment and social roles, e.g. child rearing [2, 6]. Further, RA and FM are associated with poor psychological functioning with 20 to $60 \%$ reporting depressive symptoms [7-9]. It is clear that there is a widespread impact of RA and FM on physical, psychological and social factors in affected individuals, and thus, outcome measures that encompass multiple aspects of quality of life are needed.

In this volume, Birtane et al. [10] study the use of a generic measure of physical and psychological functioning in patients with RA and FM and thus provide insights on the quality of life outcomes in these disorders. Generic and selfreport measures of quality of life provide a wealth of information regarding the experience of individuals with rheumatic conditions that medical and observational measures cannot capture [11]. One such measure is the Medical Outcomes Survey 36 Items (SF-36) [12], which is a selfreport multidimensional measure of quality of life that has been used extensively in RA and FM research [13, 14]. The SF-36 includes subscales across eight dimensions of health and well-being, including physical functioning, role physical, role emotional, bodily pain, general health, vitality, social functioning and mental health. Scores for all subscales are expressed on a scale of 0 to 100 , with a higher score indicating a better state of health. It has good reliability and validity for both clinical and healthy community-based samples [15].

A generic measure of quality of life can offer a number of insights into the impact of rheumatic conditions on 
everyday functioning. The SF-36 provides the opportunity for interesting comparisons of the quality of life between healthy individuals and those with rheumatic conditions and other chronic physical conditions. Studies indicate that those with RA and FM, almost invariably, have reduced or compromised quality of life compared to healthy agematched controls. Both RA and FM have a similar impact on psychological and physical functioning and social roles as other chronic conditions that contribute to the global burden of diseases, such as heart disease, chronic obstructive pulmonary disease and diabetes [10, 16, 17]. These findings have implications on health policy and allocation of funding for both healthcare and research. For instance, musculoskeletal conditions affect more than $17 \%$ of the community and $60 \%$ of working-aged adults, with projections indicating that arthritis will affect up to $20 \%$ of people by 2020 [18]. The prevalence, cost and burden of musculoskeletal disorders indicate that policymakers need to address the impact on economies, healthcare systems and society at large. For instance, if a public health intervention in 2005 enabled the onset of arthritis to be delayed by 10 years, the age-related incidence rates would be reduced by $11.1 \%$ before 2020 [18]. The burden of musculoskeletal disorders and issues of impaired quality of life have become an international health priority with initiatives such as the Bone and Joint Decade launched by the World Health Organization (WHO).

Birtane's use of a generic measure of quality of life highlights the fact that FM, a condition with unclear pathophysiology, is associated with impaired quality of life to a similar extent as RA. This is in keeping with the recent models of quality of life or disability that place less emphasis on disease processes, pathophysiology and/or structural damage. Previous models of outcomes for rheumatic conditions have a strong biomedical focus with many models of disability or quality of life having an implicit assumption that there is a linear relationship between disease processes and disability. Attempting to use such models of disability by reading from left to right has obvious shortcomings because there are many instances such as FM that do not have a fully identifiable disease process [19]. Indeed, focusing on pathophysiology and functional ability in a limited context without consideration of the individual's everyday tasks and roles sheds little light on the quality of life [20].

Newer approaches to examining disability acknowledge the roles of demographic, physiological, psychological, social and environmental factors acting as buffers and exacerbators of poor outcomes for chronic physical conditions [2]. The International Classification of Functioning (ICF) promoted by the WHO incorporates a broader biopsychosocial framework of disability, health and health-related states [21]. Indeed, the ICF takes a neutral stand with regard to aetiology and allows researchers to arrive at causal inferences using appropriate scientific methods. The ICF attempts to dislodge assumptions that the body level dysfunctioning, classified as impairments, is the fundamental dimension of disability and quality of life [21-23]. In other words, the quality of life in both RA and FM is not contingent on aetiology. The presence of a disability implies a cause, but the cause may not be sufficient to explain the resulting quality of life [21, 24, 25]. Measures such as the SF-36 provide the building blocks to create models of quality of life and study the different perspectives of this process across a range of chronic physical conditions as well as healthy individuals. Within this framework, using generic measures of quality of life can offer opportunities to frame research and interventions that appropriately target the quality of life of individuals with musculoskeletal disorders.

Using this approach, Birtane et al. [10] identified in patients with RA and FM that the incidence of poor physical and psychological functioning is almost invariably greater than for healthy controls. Additionally, higher depression levels are evident in patients with FM compared to those with RA. It is not surprising that FM is associated with the worst psychological functioning, given that depression is often evident in individuals with FM [26]. These observations are consistent with previous findings, which indicate that significant depressive symptoms are reported by up to $60 \%$ of individuals with chronic physical conditions. Addressing poor psychological functioning, especially depression, in musculoskeletal conditions is critical due to its impact on the condition itself. Reciprocal relationships can occur between depression and pain and disability leading to a cycle of poor mental and physical health. Depression is related to poor treatment compliance and increased morbidity and mortality in rheumatic conditions [27]. Measures such as the SF-36 clearly identify the associations between chronic physical conditions and mental health and further highlight the importance of addressing psychological functioning in both research and interventions to ultimately improve the individuals' quality of life.

RA and FM are of course not mutually exclusive. The pathophysiology of each disorder is different, and many patients with RA also have FM, as do many other patients with a variety of chronic rheumatic diseases. The substrate of FM lies in the pain system, which can be functionally activated by distress, a common feature of chronic painful and disabling disorders. How much of the FM mechanism contributes to the low quality of life of RA? Further exploration of the mechanisms causing FM, with its resultant highly significant effect on the quality of life, will have a great impact on the management of not only FM itself but also RA and related musculoskeletal conditions. 


\section{References}

1. Allaire S, Wolfe F, Niu JB, Lavalley M, Michaud K (2005) Work disability and its economic effect on 55-64 year old adults with rheumatoid arthritis. Arthritis Rheum 53:603-608

2. Verbrugge LM, Juarez L (2006) Profile of arthritis disability: II. Arthritis Care Res 55:102-113

3. Arnett F, Edworthy S, Bloch D, McShane D, Fries J, Cooper N, Healy L, Kaplan S, Liang M, Luthra H, Medsger T, Mitchell D, Neustadt D, Pinals R, Schaller J, Sharp J, Wilder R, Hunder G (1988) The American Rheumatism Association 1987 revised criteria for the classification of rheumatoid arthritis. Arthritis Rheum 31:315-324

4. Weir P, Harlan G, Nkoy F, Jones S, Hegmann K, Gren L, Lyon J (2006) The incidence of fibromyalgia and its associated comorbidities: a population-based retrospective cohort study based on International Classification of Diseases, 9th revision codes. J Clin Rheumatol 12:124-128

5. Lawrence R, Helmick C, Arnett F, Deyo R, Felson D, Giannini E, Heyse S, Hirsch R, Hochberg M, Hunder G, Liang M, Pillemer S, Steen V, Wolfe F (1998) Estimates of the prevalence of arthritis and selected musculoskeletal disorders in the United States. Arthritis Rheum 41:778-799

6. Reisine S, Goodenow C, Grady K (1987) The impact of rheumatoid arthritis on the homemaker. Soc Sci Med 25:89-95

7. Dickens C, McGowan L, Clark-Carter D, Creed F (2002) Depression in rheumatoid arthritis: a systematic review of the literature with meta-analysis. Psychosom Med 64:52-60

8. Hornbrook MC, Goodman MJ (1996) Chronic disease, functional health status, and demographics - a multi-dimensional approach to risk adjustment. Health Serv Res 31:283-307

9. McWilliams LA, Cox BJ, Enns MW (2003) Mood and anxiety disorders associated with chronic pain: an examination in a nationally representative sample. Pain 106:127-133

10. Birtane M, Uzunca K, Tastekin N, Tuna H (in press) The evaluation of quality of life in fibromyalgia syndrome: a comparison with rheumatoid arthritis by using SF-36 health survey. Clin Rheumatol

11. Wolfe F, Michaud K, Gefeller O, Choi HK (2003) Predicting mortality in patients with rheumatoid arthritis. Arthritis Rheum 48:1530-1542

12. Ware J, Sherbourne C (1992) The MOS 36-item short-form health survey (SF-36). Med Care 30:473-481

13. Guillemin F (2000) Functional disability and quality-of-life assessment in clinical practice. Rheumatol 39:17-23
14. Jason L, Taylor R, Kennedy C (2000) Chronic fatigue syndrome, fibromyalgia, and multiple chemical sensitivities in a communitybased sample of persons with chronic fatigue syndrome-like symptoms. Psychosom Med 62:655-663

15. McCallum J (1994) The new "SF-36" health status measure: Australian validity tests. In: National Centre for Epidemiology and Population Health, Australian National University, Canberra

16. Australian Bureau of Statistics (1998) National Survey of Mental Health and Wellbeing. Australian Bureau of Statistics, Canberra, Australia

17. Verbrugge L, Patrick D (1994) Seven chronic conditions: their impact on US adults' activity levels and use of medical services. Am J Public Health 85:173-182

18. Access Economics Pty Ltd (2005) Arthritis - the bottom line: the economic impact of arthritis in Australia. In: Arthritis Australia, Sydney, Australia, p 50

19. Chamie M (1995) What does morbidity have to do with disability? Disabil Rehabil 17:323-337

20. Maly MR, Costigan PA, Olney SJ (2006) Determinants of selfreport outcome measures in people with knee osteoarthritis. Arch Phys Med Rehabil 87:96-104

21. World Health Organization (2002) International classification of functioning, disability and health (ICF). In: World Health Organization, Geneva

22. Weigl M, Cieza A, Andersen C, Kollerits B, Amann E, Stucki G (2004) Identification of relevant ICF categories in patients with chronic health conditions: a Delphi exercise. J Rehabil Med $36: 12-21$

23. Cieza A, Stucki G, Weigl M, Kullmann L, Stoll T, Kamen L, Kostanjsek N, Walsh N (2004) ICF core sets for chronic widespread pain. J Rehabil Med 36:63-68

24. Odding E, Valkenburg H, Algra D, Vandenouweland F, Grobbee D, Hofman A (1995) Association of locomotor complaints and disability in the Rotterdam study. Ann Rheum Dis 54:721-725

25. Vlieland T, Buitenhuis N, Vanzeben D, Vandenbroucke J, Breedveld F, Hazes J (1994) Sociodemographic factors and the outcome of rheumatoid arthritis in young women. Ann Rheum Dis 53:803-806

26. Wolfe F, Smyth H, Yunus M, Bennet R, Bombardier C, Goldenbur D, Tugwell P, Campbell S, Franklin C, Gatter R, Hamaty D, Lessard J, Lichbroun A, Masi A, McCain W, Reynolds J, Romano T, Russel J, Sheon R (1990) The American College of Rheumatology 1990 criteria for the classification of fibromyalgia. Arthritis Rheum 33:160-172

27. Ang DC, Choi H, Kroenke K, Wolfe F (2005) Comorbid depression is an independent risk factor for mortality in patients with rheumatoid arthritis. J Rheum 32:1013-1019 